\title{
Brain Temperature in Patients With Chronic Hydrocephalus After Subarachnoid Hemorrhage
}

\author{
Tomoaki OMORI, Yutaka HIRASHIMA, Nobuo OKA*, Shigenori TAKEDA, \\ Yoshiki MINO, Jun HARADA, and Shunro ENDO
}

Department of Neurosurgery, Toyama Medical and Pharmaceutical University, Toyama; * Department of Neurosurgery, Oka Neurosurgical Hospital, Machida, Tokyo

\begin{abstract}
The relationships between temperature indices and clinical condition on admission or improvement after ventriculoperitoneal (VP) shunting were evaluated in patients with subarachnoid hemorrhage (SAH). Brain temperatures were measured at intervals of $1 \mathrm{~cm}$ from the brain surface to the lateral ventricle at shunt operation. Rectal temperature was also measured. The difference between intraventricular and rectal temperatures was correlated with age $(p=0.0486)$, Glasgow Coma Scale $(p=0.0129)$, Hunt and Hess grade $(p=0.0101)$, and improvement score after VP shunting $(p=0.0104)$. Measurement of brain temperature may predict the outcome of VP shunting in patients with SAH.
\end{abstract}

Key words: brain temperature, chronic hydrocephalus, dementia, shunt surgery, subarachnoid hemorrhage

\section{Introduction}

Cerebral hypothermia can reduce the extent of neuronal damage after ischemia, subarachnoid hemorrhage $(\mathrm{SAH})$, and trauma in human and experimental models, ${ }^{1,2,9,11)}$ although the complications may outweigh the potential benefit of moderate hypothermia. ${ }^{3)}$ These findings have promoted renewed interest in human brain temperature. Many clinical studies have set out to assess the effectiveness of moderate hypothermia in improving neurological outcome after head injury.,10) However, there is little information regarding human brain temperature, especially in the normal state and in the chronic stage after cerebrovascular disease and head injury. ${ }^{5)}$

The present study measured brain temperature in patients with chronic hydrocephalus after $\mathrm{SAH}$ and investigated the relationship between brain temperature and efficacy of ventriculoperitoneal (VP) shunting.

\section{Patients and Methods}

This study included 12 patients with chronic hydrocephalus after SAH who were admitted to the Toyama Medical and Pharmaceutical University

Received April 9, 2003; Accepted August 5, 2003
Hospital between January 1993 and April 1995 (Table 1). All patients had undergone aneurysmal clipping within 72 hours after the onset of SAH. Clinical condition on admission was evaluated according to the Hunt and Hess classification ${ }^{6)}$ and the Glasgow Coma Scale. ${ }^{12)}$ The severity of SAH was assessed according to Fisher's classification. ${ }^{4)}$ Informed consent for this study was obtained from each patient or family.

Placement of a VP shunt was decided based on the following criteria ${ }^{5)}$ : Clinical symptoms consistent with normal pressure hydrocephalus (dementia, gait disturbance, or urinary incontinence in any combination); absence of evidence of toxic or metabolic disturbances; and all of the following three criteria, a) characteristic cisternographic pattern (ventricular reflux and blockage of convexity flow), b) computed tomography characteristics of positive diagnostic value (enlarged ventricles and periventricular lucency), and c) clinical improvement from single or repetitive lumbar cerebrospinal fluid drainage. No patients had infection at the time of brain temperature measurement. The interval between the onset of SAH and VP shunting was $52.6 \pm 24.6$ days $(\mathrm{n}=12)$.

Improvement of dementia, gait disturbance, and urinary incontinence were evaluated 3 months later. An improvement score was established using objective examinations such as Mini-Mental State 
Table 1 Summary of patient data

\begin{tabular}{|c|c|c|c|c|c|c|c|c|c|}
\hline $\begin{array}{l}\text { Case } \\
\text { No. }\end{array}$ & $\begin{array}{l}\text { Agel } \\
\text { Sex }\end{array}$ & $\begin{array}{l}\text { Hunt and Hess } \\
\text { grade }\end{array}$ & $\begin{array}{l}\text { Fisher } \\
\text { Group }\end{array}$ & $\begin{array}{l}\text { Glasgow Coma } \\
\text { Scale score }\end{array}$ & $\begin{array}{l}\text { Improvement } \\
\text { score }\end{array}$ & $\begin{array}{l}\text { Site of ruptured } \\
\text { aneurysm }\end{array}$ & $\begin{array}{l}\mathrm{Tv} \\
\left({ }^{\circ} \mathrm{C}\right)\end{array}$ & $\begin{array}{c}\Delta \mathrm{v}-\mathrm{b} 2 \\
\left({ }^{\circ} \mathrm{C}\right)\end{array}$ & $\begin{array}{c}\Delta \mathrm{v}-\mathrm{r} \\
\left({ }^{\circ} \mathrm{C}\right)\end{array}$ \\
\hline 1 & $75 / \mathrm{F}$ & II & 2 & 13 & 2 & MCA & 37.2 & 1.4 & 0.3 \\
\hline 2 & $79 / \mathrm{M}$ & IV & 4 & 8 & 0 & AcoA & 36.7 & 1.0 & -0.1 \\
\hline 3 & $40 / \mathrm{M}$ & II & 3 & 13 & 3 & MCA & 37.1 & 0.3 & 1.3 \\
\hline 4 & $50 / \mathrm{F}$ & III & 3 & 10 & 2 & AcoA & 37.3 & 0.7 & 0.7 \\
\hline 5 & $80 / F$ & III & 4 & 12 & 3 & $\mathrm{ACA}$ & 37.5 & 0.6 & 0.5 \\
\hline 6 & $59 / F$ & II & 2 & 15 & 2 & ICA-PcoA & 37.1 & 1.8 & 0.6 \\
\hline 7 & $69 / F$ & II & 2 & 14 & 3 & AcoA & 37.3 & 1.0 & 0.6 \\
\hline 8 & $73 / \mathrm{F}$ & III & 3 & 10 & 1 & AcoA & 36.6 & 2.7 & -0.1 \\
\hline 9 & $46 / \mathrm{M}$ & III & 4 & 10 & 1 & VA & 37.3 & 0.8 & 0.4 \\
\hline 10 & $73 / \mathrm{F}$ & IV & 3 & 7 & 2 & ICA-PcoA & 37.3 & 1.1 & -0.1 \\
\hline 11 & $70 / F$ & IV & 4 & 7 & 1 & MCA & 38.1 & 0.9 & -0.2 \\
\hline 12 & $75 / F$ & IV & 3 & 8 & 0 & ICA bifurcation & 37.2 & 0.7 & -0.3 \\
\hline
\end{tabular}

ACA: anterior cerebral artery, AcoA: anterior communicating artery, $\Delta \mathrm{v}-\mathrm{b} 2$ : the difference between intraventricular temperature and brain temperature at $2 \mathrm{~cm}$ depth from the brain surface, $\Delta \mathrm{v}-\mathrm{r}$ : the difference between intraventricular and rectal temperatures, ICA: internal carotid artery, MCA: middle cerebral artery, PcoA: posterior communicating artery, Tv: ventricular temperature, VA: vertebral artery.

Examination, measurement of walking speed, and urodynamic study, with one point assigned for improvement of each symptom (3 points maximum). The relationships were evaluated between temperature indices and clinical condition on admission or improvement score after VP shunting.

Brain temperature was measured with a copperconstantan thermocouple, covered and isolated with a thin Teflon layer, and introduced at the tip of a Dandy's cannula (Biomedical Science, Kanazawa). The thermocouple was tested in a thermostatistically-controlled water bath to verify accuracy over a temperature ranging between $30^{\circ} \mathrm{C}$ and $45^{\circ} \mathrm{C}$. The error of measurement was $\pm 0.1^{\circ} \mathrm{C}$.

In principle, the cannula was inserted through a right frontal burr hole placed $3.0 \mathrm{~cm}$ lateral to the midline, immediately behind the coronal suture. Intracerebral temperature was measured at intervals of $1 \mathrm{~cm}$ from the surface of the brain to the anterior horn of the lateral ventricle at the time of ventricular tapping. VP shunting was performed under general anesthesia using $66 \% \mathrm{~N}_{2} \mathrm{O}$ and $1-2 \%$ isoflurane in oxygen.

The study performed in the water bath showed that temperature readings were stabilized within 30 seconds in the range from $28^{\circ} \mathrm{C}$ to $37^{\circ} \mathrm{C}$ or $45^{\circ} \mathrm{C}$ to $37^{\circ} \mathrm{C}$. Therefore, the cannula was held by hand for one minute to obtain a stable reading at each measurement point in the brain. The accuracy of the thermocouple did not change at examination every 6 months. Room temperature ranged from $23.5^{\circ} \mathrm{C}$ to $28.0^{\circ} \mathrm{C}\left(25.5 \pm 1.67^{\circ} \mathrm{C}, \mathrm{n}=12\right)$.

Commercially available thermocouples were used for rectal temperature measurement at 3 to $4 \mathrm{~cm}$ proximal to the anal sphincter (Nihon Koden, Tokyo). Brain temperature indices included intraventricular temperature (Tv), the difference between ventricular temperature and brain temperature at $2 \mathrm{~cm}$ depth from the brain surface $(\Delta \mathrm{v}-\mathrm{b} 2)$, and the difference between intraventricular and rectal temperatures $(\Delta v-r)$.

Values are presented as mean \pm SD. The relationship between age and brain temperature index was evaluated by determination of Spearman's rank correlation. The relationship between $\Delta \mathrm{v}-\mathrm{r}$ and Hunt and Hess classification, ${ }^{6)}$ Glasgow Coma Scale, ${ }^{12)}$ Fisher's classification, ${ }^{4)}$ or improvement score after VP shunting were also evaluated by determination of Spearman's rank correlation. Values of $p<0.05$ were considered as statistically significant.

\section{Results}

The ventricular temperature and temperature indices in all patients are shown in Table 1. The relationship between $\Delta \mathrm{v}-\mathrm{r}$ and improvement score after VP shunting showed a significant correlation ( $\mathrm{p}=0.0104)$ (Fig. 1). $\Delta \mathrm{v}-\mathrm{r}$ was negatively correlated with age ( $\mathrm{p}=0.0486$ ) (Fig. 2). There was no significant correlation between Fisher's classification of $\mathrm{SAH}$ and $\Delta \mathrm{v}-\mathrm{r}$. However, significant correlations were observed between Glasgow Coma Scale $(p=0.0129)$ or Hunt and Hess classification $(\mathrm{p}=0.0101)$ and $\Delta \mathrm{v}-\mathrm{r}$ (Fig. 3). No significant correlation was observed between $\mathrm{Tv}$ or $\Delta \mathrm{v}-\mathrm{b} 2$ 


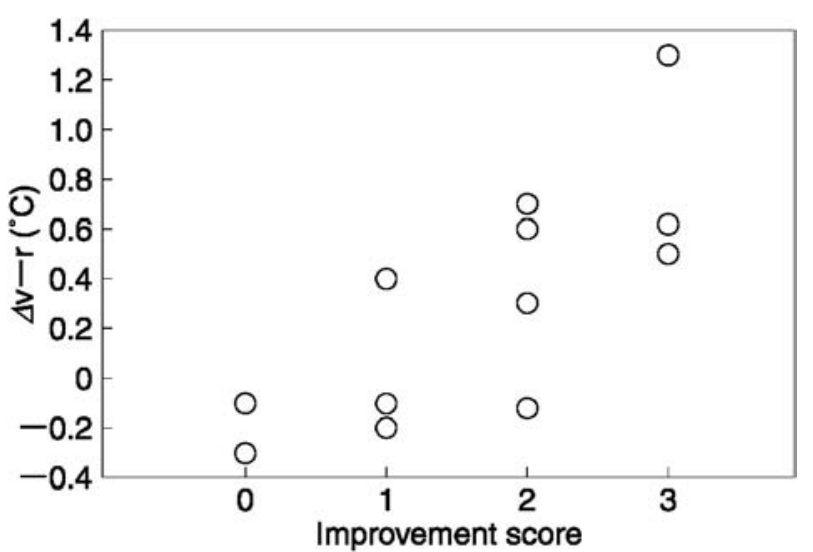

Fig. 1 Relationship between improvement score at 3 months after ventriculoperitoneal shunt and the difference between ventricular and rectal temperatures $(\Delta v-r)$ showing a significant correlation $(p=\mathbf{0 . 0 1 0 4}$, Spearman's rank correlation). The improvement score was based on one point for improvement of dementia, gait disturbance, or urinary incontinence ( 3 points maximum).

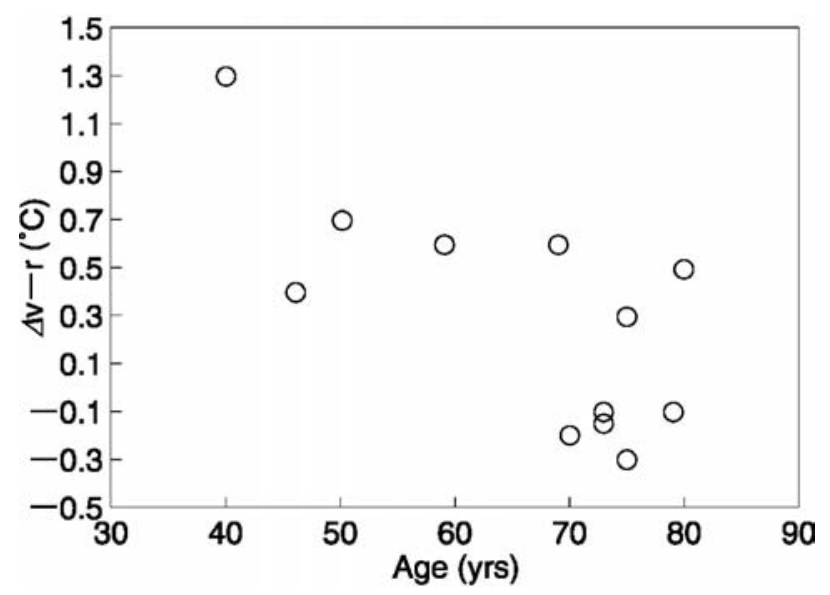

Fig. 2 Relationship between age and the difference between ventricular and rectal temperatures $(\Delta \mathbf{v}-\mathbf{r})$ showing a significant correlation ( $p=$ 0.0486, Spearman's rank correlation).

and improvement score after VP shunting, age, Fisher's classification of SAH, Glasgow Coma Scale, or Hunt and Hess classification.

\section{Discussion}

Brain temperature increases much faster than body core temperature, and the difference is greater in patients with acute neurosurgical conditions such as severe head injury and SAH. ${ }^{8)}$ Pyrexia is common in
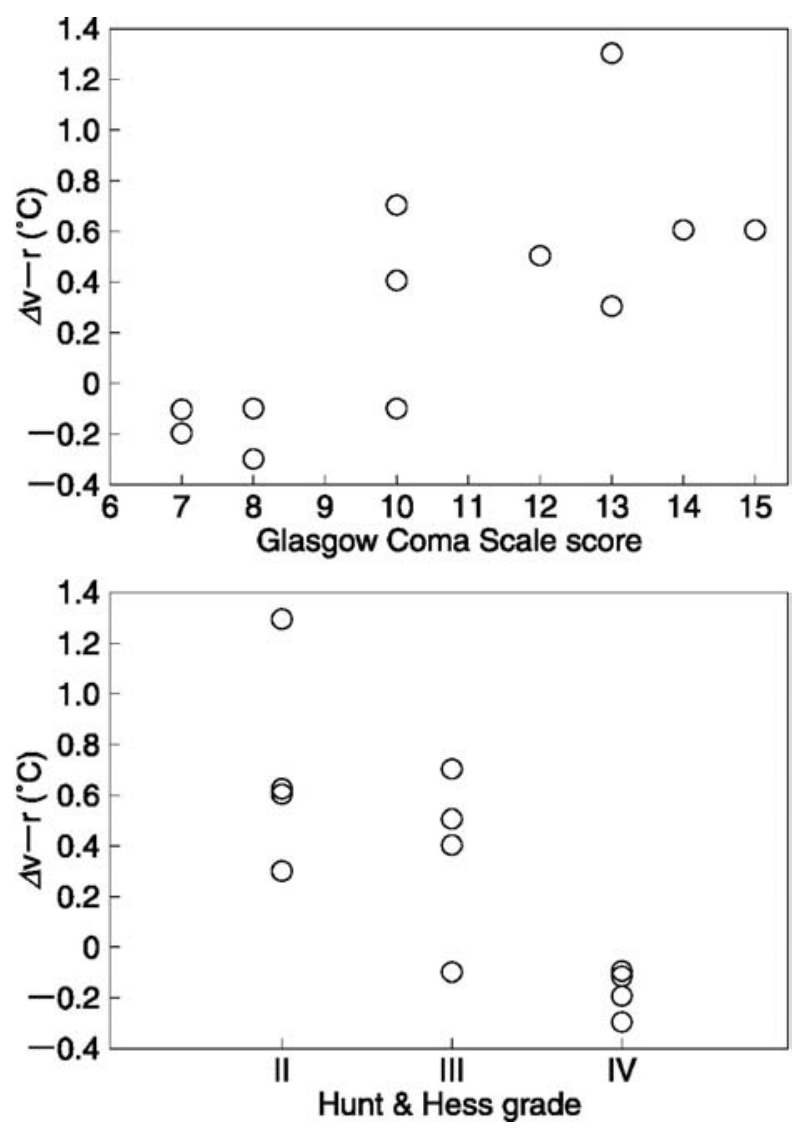

Fig. 3 Relationship between Glasgow Coma Scale score or Hunt and Hess grade and the difference between ventricular and rectal temperatures $(\Delta \mathbf{v}-\mathbf{r})$ showing significant correlations for Glasgow Coma Scale score (p = 0.0129, Spearman's rank correlation) and Hunt and Hess grade $(p=0.0101$, Spearman's rank correlation).

the acute stage of severe neurological disease and cerebral metabolism increases more than systemic metabolism due to the rise in temperature. ${ }^{8)} \mathrm{We}$ previously observed that the difference between ventricular and rectal temperatures was greater in patients requiring continuous ventricular drainage for acute hydrocephalus due to $\mathrm{SAH}$, intracerebral hematoma, or brain tumor, than in patients with chronic hydrocephalus due to various etiologies. ${ }^{5)}$ However, brain temperature might vary depending on the phase of the clinical course.

Unfortunately, very little information is available on human brain temperature, and the mechanism of brain temperature control in the chronic stage of $\mathrm{SAH}$ is obscure. The temperature of the brain depends on three major factors: local heat production, cerebral blood flow, and the temperature of the perfusing blood. ${ }^{8)}$ 
This study found that improvement of symptoms due to chronic hydrocephalus by VP shunting was correlated with brain temperature. The difference between ventricular and rectal temperatures during shunt surgery in patients with better outcomes was higher than in patients with worse outcomes. The condition of the brain may be related to the recovery of symptoms after VP shunt surgery. The present study found the difference between ventricular and rectal temperatures was correlated negatively with age. Furthermore, the difference between ventricular and rectal temperatures was correlated with Glasgow Coma Scale score or Hunt and Hess grade. Reduced metabolic activity and heat production might be related to such phenomena in the brain of the aged and patients with worse neurological grade or Glasgow Coma Scale score. This hypothesis suggests that patients with lower brain metabolic activity due to severe brain damage after SAH may not obtain better recovery after shunt surgery for symptoms due to chronic hydrocephalus after SAH.

Definite conclusions cannot be drawn from the present study because of the small sample size. Further studies are required to better assess the relationship between the efficacy of shunt surgery and brain temperature.

\section{Acknowledgments}

The authors thank Ms. Tomomi Kiyohara and Mr. Yasuo Nakayama for preparing the manuscript.

\section{References}

1) Chopp M, Chen H, Dereski M, Gracia J: Mild hypothermia intervention after graded ischemic stress in rats. Stroke 20: 37-43, 1991

2) Clifton GL, Jiang J, Lyeth B, Jenkis L, Hamm R, Hayes R: Marked protection by moderate hypothermia after experimental traumatic brain injury. J Cereb Blood Flow Metab 11: 114-121, 1991

3) Clifton GL, Miller ER, Choi SC, Levin HS, McCauley S, Smith KR Jr, Muizelaar JP, Wagner FC Jr, Marion DW, Luerssen TG, Chesnut RM, Schwartz M: Lack of effect of induction of hypothermia after acute brain injury. N Engl J Med 344: 556-563, 2001
4) Fisher CM, Kistler JP, Davis JM: Relation of cerebral vasospasm to subarachnoid hemorrhage visualized by computerized tomographic scanning. Neurosurgery 6: 1-9, 1980

5) Hirashima Y, Takaba M, Endo S, Hayashi N, Yamashita K, Takaku A: Intracerebral temperature in patients with hydrocephalus of varying aetiology. J Neurol Neurosurg Psychiatry 64: 792-794, 1998

6) Hunt WE, Hess RM: Surgical risk as related to time of intervention in the repair of intracranial aneurysms. J Neurosurg 28: 14-19, 1969

7) Marion DW, Obrist WD, Carlier PM, Penrod LE, Darby JM: The use of moderate therapeutic hypothermia for patients with severe head injuries: a preliminary report. J Neurosurg 79: 354-362, 1993

8) Rossi S, Zanier ER, Mauri I, Columbo A, Stocchetti $\mathrm{N}$ : Brain temperature, body core temperature, and intracranial pressure in acute cerebral damage. J Neurol Neurosurg Psychiatry 71: 448-454, 2001

9) Schmutzhard E, Engelhardt K, Beer R, Brössner G, Pfausler B, Spiss H, Unterberger I, Kampfl A: Safety and efficacy of a novel intravascular cooling device to control body temperature in neurologic intensive care patients: A prospective pilot study. Crit Care Med 30: 2481-2488, 2002

10) Shiozaki T, Sugimoto $H$, Taneda M, Yoshida H, Iwai A, Yoshioka T, Sugimoto T: Effects of mild hypothermia on uncontrollable intracranial hypertension after severe head injury. J Neurosurg 79: 363-368, 1993

11) Takagi K, Ginsberg MD, Globus MY, Martinez E, Buso R: Effects of hyperthermia on glutamate release in ischemic penumbra after middle cerebral artery occlusion in rat. Am J Physiol 266: H1770-H1776, 1996

12) Teasdale GM, Jennett B: Assessment of coma and impaired consciousness: a practical scale. Lancet 2: 81-84, 1974

Address reprint requests to: Y. Hirashima, M.D., Department of Neurosurgery, Toyama Medical and Pharmaceutical University, 2630 Sugitani, Toyama 930-0194, Japan.

e-mail: yhira@ms.toyama-mpu.ac.jp

Commentary on this paper appears on the next page. 


\section{Commentary}

The observations by Omori et al. are indeed very original. They have documented a relationship between clinical outcome after shunting in post SAH patients and brain temperature index (difference between brain and rectal temperature). In essence, the warmer the brain, in relative terms, the better the clinical outcome. Brain temperature is now relatively easy to measure through ventricular catheters and parenchymal pressure monitors, and could add to the armamentarium of physiologic parameters intraoperatively and in the intensive care unit. The authors interpret these observations in light of possible brain metabolism levels, with cooler brain likely reflecting decreased brain activity. This speculation is reasonable, since the same temperature index also correlated inversely with age (itself a negative prognostic indicator after SAH), and directly with neurologic status on GCS (itself a positive prognostic indicator after SAH). The authors are encouraged to confirm these results in a larger cohort of patients. Also, they should correlate this temperature index with brain blood flow and metabolism on functional imaging, and with other clinical parameters of severity of illness. It remains to be seen if this temperature index is an additional prognostic indicator, independent of other clinical parameters (such as age and GCS), or simply reflects severity of illness as mirrored by other evident factors. This will be important to assess the independent utility of this index as a prognostic gauge.

Issam A. AwAD, M.D., M.Sc., F.A.C.S. Professor of Neurosurgery Northwestern University Feinberg School of Medicine Evanston Northwestern Healthcare Evanston, Illinois, U.S.A.

The authors have measured brain and rectal temperature of 12 patients who underwent VP shunting due to chronic hydrocephalus after SAH. The difference between ventricular and rectal temperature which varied between 1.3 and $-0.3^{\circ} \mathrm{C}$ was considered as a key parameter and correlated with the improvement score after VP shunting, age, and initial clinical condition. As the result of the shunting procedure was better in patients with a higher brain temperature index, the authors hypothesized that a reduced cerebral metabolic activity and heat production may be the underlying cause of less favorable outcome after VP shunting, and probably the result of more severe brain damage from the initial SAH. According to these results, intraoperative measurement of brain temperature is believed to predict the outcome of shunting procedure after SAH. Such a conclusion seems logic in light of the present data. The statistical results should be interpreted with caution, though, since other factors that have not been considered in the present study may influence the outcome of VP shunting as well. Nevertheless, I would like to encourage the authors to continue their systematic investigations of brain temperature in various pathologic conditions, and possibly also in the normal state.

Helmut BERTALANFFY, M.D. Department of Neurosurgery Philipps University Hospital Marburg, Germany

The authors have shown interesting correlations between brain temperature (or the difference between brain and rectal temperatures, which presumably more accurately reflects brain temperature or metabolism at the time of measurement) at the time of ventricular shunting, and the clinical effect of the procedure measured three months later, in patients with communicating hydrocephalus after aneurysm hemorrhage. It is fascinating that the clinical grade and GCS, estimated at the time of hemorrhage, still showed correlation with this temperature difference an average of 53 days after the onset.

The association of a higher brain temperature with a higher GCS and better grade supports the concept of suppression of brain metabolism in the worst affected patients. Conversely, a higher brain temperature, i.e. less metabolic suppression, was associated with a better outcome of shunting, implying that the clinical effect of the hydrocephalus was not itself related to metabolic suppression.

The inverse correlation of brain temperature with age is also noted, and suggests a more active metabolism in younger individuals. As noted by the authors, more work is needed on the whole question of brain temperature and metabolism, and it will be important to see if these results are confirmed with larger numbers of cases. It would be interesting also to see whether brain temperature is correlated with clinical state, measured by GCS or Mini-Mental State, at the time of shunting, as well as on admission.

Nicholas W. C. DorsCH, M.D., F.R.C.S., F.R.A.C.S. Department of Neurosurgery Westmead Hospital Sydney, Australia 